\title{
Exploring Elementary Pre-Service Teachers' Experiences and Learning Outcomes in a Revised Inquiry-Based Science Lesson: An Action Research
}

\author{
Mahsa Kazempour ${ }^{1} \&$ Aidin Amirshokoohi ${ }^{2}$ \\ ${ }^{1}$ Department of Early Childhood \& Elementary Education, Penn State Berks, Reading, USA \\ ${ }^{2}$ DeSales University in Center Valley, USA \\ Correspondence: Mahsa Kazempour, Department of Early Childhood \& Elementary Education, Penn State Berks, \\ Reading, PA, USA. Tel: 1-610-396-6312. E-mail: muk30@psu.edu
}

Received: March 19, $2013 \quad$ Accepted: April 2, $2013 \quad$ Online Published: May 2, 2013
doi:10.5539/jel.v2n2p144

\begin{abstract}
In order for teachers to implement inquiry-based teaching practices, they must have experienced inquiry-based learning especially during science content and methods courses. Although the impacts of inquiry-based instruction on various cognitive and affective domains have been studied and documented little attention has been paid to how PSTs experience inquiry in these classrooms. The aim of this action research project was to explore our instructional strategies and elementary PSTs' learning experiences as we developed and implemented an inquiry-based lesson in a science content course for elementary education students. Video observation data, instructor reflections, and student reflections were analyzed to shed light on students' conceptual understanding of the physical science concept, their learning experiences including team interactions, motivation and interest, and concerns and frustrations, as well as the role of the instructor in the revised lesson.
\end{abstract}

Keywords: action research, pre-service teachers, inquiry, teacher education, science content course, learning experience

\section{Introduction}

The science education community's focus on inquiry-based science instruction is reflected in numerous national and statewide reform initiatives such as the National Research Council's (1996) National Science Education Standards (NSES). According to the NSES, inquiry ought to be addressed as a science instructional approach and science content by immersing students in various tasks and cognitive processes that scientists are constantly involved in including making observations, asking questions, planning and conducting investigations, collecting and analyzing data, and proposing and communicating explanations. Learning science through inquiry "requires identification of assumptions, use of critical and logical thinking, and consideration of alternative explanations (NSES, p. 23).”

Additionally, the teaching standards in the NSES document further emphasize the value of educating and encouraging teachers to engage students in inquiry-based learning experiences as described above (NRC, 2000). In order for teachers to implement inquiry-based teaching practices, they must themselves possess an adequate understanding of the process of scientific inquiry and inquiry-based instruction. Unfortunately, for many teachers, inquiry-based instruction may pose a tremendous challenge mainly because they have had little or no inquiry-based science learning experience during both their K-12 education and teacher preparation programs (Loucks-Horsley, Hewson, Love, \& Stiles, 1998, 2003). This holds particularly true for elementary teachers who have historically been shown to be more reluctant or ill equipped to teach science or to do so as aligned with the current inquiry-centered reform initiatives (Author1; Ginns \& Watters, 1990; Riggs, 1991). Furthermore, elementary pre-service teachers tend to view physical sciences, including physics and chemistry, as the most difficult and challenging areas in science (Abell \& Bryan, 1997).

Encouraging teachers to incorporate inquiry-based teaching in their classrooms will be futile if they lack an understanding of what inquiry-based learning and teaching should look like. This lack of understanding on the part of teachers will often lead to feeling detached and their inability to create such learning environments. Therefore, it is imperative that teacher candidates, particularly elementary pre-service teachers (PSTs), gain 
firsthand experience and develop a more in-depth understanding of inquiry-based learning as part of their training, especially in science content courses, so as not to replicate and reinforce their previous traditional science experiences. How elementary PSTs experience science and learning in such settings will be extremely critical in shaping how they teach science concepts in their future classrooms.

Numerous studies in the science education literature document the impact of inquiry or reform-based teacher education courses on PSTs' attitude toward science and science teaching, views of nature of science, beliefs about science and science teaching, self-efficacy, and content knowledge (e.g., Author; Palmquist \& Finley, 1997; Riggs, 1991). The majority of these studies have focused on science methods courses. Further attention should be directed to exploring science content courses and gauging the types of experiences elementary PSTs have in such settings. Although the impact of inquiry-based instruction on various cognitive and affective domains have been studied and documented, little attention, has been given to how PSTs experience inquiry in such classrooms which may influence their views, attitudes, and beliefs as well as their future science instructional approach.

A closer examination of elementary PSTs' science content learning experiences through inquiry will enable us, as science educators, to offer them more effective learning opportunities that will enhance their understanding and skills of inquiry-based science learning and instruction. In our role as science educators, we may inadvertently overlook or ignore critical components in our classrooms such as countless moments of candidates' team discussions and interactions. The portions of the dialogues and interactions that we partake offer valuable snippets of students' thinking, roles, understanding, and decision-making. What can examining and reflecting on these snippets of conversation and interaction between the instructor and teams indicate about our students' process of learning, understanding of science concepts and inquiry, concerns, and cognitive skills such as critical thinking and decision making? What can they reveal about our roles as instructors in the process? Science is socially constructed and so is students' knowledge of science concepts; therefore, it is vital to focus on the often-neglected dynamics of this social learning process and students' experiences and interactions in such collaborative learning contexts. Understanding the dynamics of elementary PSTs' inquiry-based learning experiences in a science content course and examining the aforementioned questions were the focus of this action research study. We embarked on an action research to explore our instruction and students' learning experiences as we modified one of the physical science content course activities into an inquiry-based one.

Action research is most popularly described as a cyclical, systematic, and reflective process of planning, acting, observing, and reflecting aimed at 1) examining and improving one's teaching practice and 2) contributing to our collective understanding of teaching and learning through the dissemination of the findings (Carr \& Kemmis, 1986; Feldman \& Minstrell, 2000). In this study, we utilized the model of action research proposed by Kemmis (1988), a cyclical process of reconnaissance, planning, first action step, monitoring, reflecting, rethinking, and evaluation. Although action research can be an individual endeavor, it is often a collaborative effort among educators who embark on a process of critical reflection and problem solving in search of solutions to concerns and inquiries as relevant to their immediate situations.

Since as early as the mid- $20^{\text {th }}$ century, there has been a rising interest and an effort to promote the direct involvement of teachers in research and enrichment of professional practice (Carr \& Kemiss, 1986; Elliott, 1991; Noffke, 1997; Stenhouse, 1975). Teacher action research, has gained popular support and promotion in recent science education reform initiatives. The NSES, for instance, place an enormous emphasis on reflective practice by science teachers and encourage them to "approach their teaching in a spirit of inquiry-assessing, reflecting on, and learning from their own practice" (NRC, 1996, p. 42). According to Feldman and Minstrell (2000), action research has been actively pursued in "three domains of science education: teacher education and professional development; research on science learning; and curriculum development and implementation (p.2)". Self-study practices, in the form of action research by PSTs completing teacher preparation programs (Capobianco, 2007; Feldman \& Capobianco, 2000; Hewson et al., 1999; van Zee, 1998), have been on the rise in recent decades. Finally, a number of self studies and teacher action research projects have also focused on science educators as researchers (Buck \& Cordes, 2005; Capobianco, 2007; Loughran, 1996; Rice \& Roychoudhury, 2003; van Zee, Lay, \& Roberts, 2003) who utilize "systematic, self-critical inquiry" (Capobianco, 2007) to explore and improve their teaching practices and students' learning experiences. Similarly, we decided to embark on this action research study because we were keenly interested in exploring and further improving the science learning experiences of the elementary PSTs enrolled in our sections of a physical science content course. 


\section{Method}

\subsection{Context}

This action research project took place in two sections of a science content course that the authors taught at a large Midwestern university. The course, Introduction to Scientific Inquiry, is the first of three required science content courses in the elementary education program and consists of mainly freshmen and sophomore students. There were 22 (one male) and 23 (two males) students in the first and second author's sections respectively.

\subsubsection{Process of Revising the Lesson}

This study focused on a lesson on chemical changes that was part of a four-lesson unit on matter. The original lesson focused only on chemical reactions while ignoring physical changes. The one-day lesson was a typical cookbook, teacher and textbook directed, confirmation lab that began with an introductory section, including the definition and indicator signs of chemical reactions, which the students were asked to read prior to coming to class. In class, students performed nine reactions and recorded their observations in a chart provided on the handout. At the end of the activity, students identified the type of chemical reaction and wrote a balanced equation for each reaction. We had previously observed and were concerned that students: 1) followed the lab instructions without paying attention to what they were doing or having any serious discussions as a team, 2) were uncertain about what they had to record in the data table, and 3) became frustrated and confused at the end of the lesson when they had to translate what they had recorded in the data table into chemical equations which they then had to balance and identify as one of the four reaction types. The lab assumed that students had completed the background reading, received prior lecture, and had full understanding of the reactions and balancing equations before beginning the lesson. This created an environment in which students rushed to simply complete the nine quick tests, record the necessary items on the chart, and then struggle with writing their concluding statements on what they had learned.

We brainstormed ways to transform the activity into an inquiry-based one that would allow students to be actively involved in their learning and utilize critical thinking skills to understand the concepts through exploration, discussion, and application. We eliminated the cookbook instructions that required minimal thinking and developed a multi-stage lesson. Finally, in an effort to allow students the opportunity to gain a deeper comprehension of the concepts, we decided to narrow the focus of the lesson to understanding the different types of change in matter (physical and chemical) and postpone the writing and balancing of equations to a subsequent lab.

The newly designed lesson was developed as a two-day inquiry-based lesson following the $5 \mathrm{E}$ learning cycle model (Bybee, 1997), a cyclical process of engagement, exploration, explanation, elaboration, and evaluation. Because we were faced with time restrictions, our 5E lesson did not consist of multiple exploration and explanation stages as recommended in the learning cycle model. Upon completion of the preceding activity on characteristics of matter, the modified lesson began with an engage stage consisting of an attention-grabbing demonstration displaying a few examples of changes in matter. Students were asked to record their observations and explain whether and how change had occurred. In order to ascertain our students' prior knowledge on the topic, we also asked them to record what they already knew about changes in matter. We then explained that we were embarking on a lesson to explore this topic further and displayed the following scenario on the screen:

You are a group of scientists from several centuries ago. You are interested in exploring the type of changes that occur in matter. The scientific community at your time has a basic understanding of changes in matter and has categorized them into two groups: A physical change involves a change in the appearance of a substance whereas a chemical change is a change in the identity of the substance. Your task is to work as a team of scientists to refine this information and come up with specific set of criteria for distinguishing between the two types of changes.

At this point, students were provided a more detailed set of instructions and began carrying out a series of tests, which included examples of both types of change. While doing so, they used their individually devised charts to record and organize their predictions and observations for each experiment. Upon completing this step, they began to discuss and analyze their observations, seeking patterns that could lead to possible criteria to distinguish between physical and chemical changes. Once they had performed this crucial step, they were asked to return to the initial tests and classify each as physical, chemical, or difficult to identify and then explain their rationale for each categorization. Next, each team presented its criteria and examples of physical and chemical changes to the rest of the class. This was followed with a class discussion of the commonalities and differences in the various sets of criteria and the formation of a refined class list of criteria through extensive dialogue. As a culminating activity, each team used the refined list of criteria to identify a series of everyday examples of changes in matter 
as either physical or chemical changes.

\subsection{Data Collection}

We employed a naturalistic, interpretive methodological approach, which would allow us to gain a more vivid and realistic awareness of students' learning experiences, their understanding of the concepts, and the instructors' role in the learning process. Data were triangulated through a variety of qualitative data collection approaches including video observation of the lesson, instructor reflections, and student reflections. Because we conducted the action research in our own classrooms, the terms instructor, author, and researcher will be utilized interchangeably throughout the subsequent sections.

\subsubsection{Video Observations}

A graduate student in the program videotaped each of our sections. Due to limitations such as the size of the classroom and the arrangement of the tables, we decided to only capture our interactions with the students as a whole class and with each team. Videos were transcribed and we also added our comments regarding our perceptions and thoughts at the time the events or conversations were unfolding in the classroom. Afterward, we also discussed and noted our post observation ideas about students' learning experiences, our instructional and communicative strategies, and possible modifications for subsequent semesters.

\subsubsection{Student Reflections}

Students utilized the individual laptops at their tables to record their thoughts and experiences, including possible frustrations and confusions throughout the lesson, and reflect on their learning and experiences. They were also directed to do a post lesson reflection discussing how the lesson was reflective of the nature of science and scientific inquiry as discussed earlier in the course.

\subsubsection{Instructor Reflections}

Prior to the lesson, we kept a written log of our discussions regarding the planned changes to the activity, anticipated outcomes, vision of our role(s) in the learning process, and our goals for student learning. After each day, we reflected individually and jointly on the implementation of the lesson, our observations of student interactions and learning, and our interactions with the students.

\subsection{Data Analysis}

Each of us individually analyzed the various qualitative data sources for emergent patterns and themes and held a peer-debriefing session after each stage to discuss and merge our analyses (Lincoln \& Gubba, 1985). We began the analysis with the video recordings, which were initially viewed and analyzed individually and then jointly analyzed and discussed. We then each read and reread our individual pre and post reflection notes and students' reflections followed with a joint discussion of our analysis and additional emergent themes.

\section{Results}

The following sections describe our findings pertaining to students' conceptual understanding, student experiences and the dynamics of the learning process, and our roles as the instructors in the learning process.

\subsection{Students' Conceptual Understanding}

When students were initially asked to record their prior understanding of changes in matter, most either did not mention the two types or simply identified them by name without a proper explanation. Approximately one third of the students in each section had attempted to provide a definition or description of each type, but their explanations were vague and often consisted of the actual terminology. For example, several students in each section had described a physical change as a "change in the physical nature of a substance" and a chemical change as "mixing of chemicals" and "two substances reacting together." Contrary to our initial predictions, none of the students even attempted to provide any examples of the two types.

The students' post lesson reflections indicated a growth in their understanding of physical and chemical changes. The majority of them successfully provided descriptions of the two types of changes without the use of textbook definitions. Instead, they provided simplistic descriptions based on their observations and set of criteria generated in their teams and as a whole class. Some of the ideas, such as the reversibility of the change or the production of a new substance, were key criteria that were initially difficult for many teams to grasp, but were included in all of the concluding explanations. Furthermore, in the elaboration (application) stage of the lesson, students were able to appropriately identify each given example with the type of change it represented and provided additional examples of their own. The following excerpt from a student's reflection is representative of typical student responses. 
One example of physical change would be mowing the lawn because you mow the lawn and it becomes short, it will soon grow back to normal length. An example of a chemical change is eating because when you swallow food, like French fries, it causes a reaction with saliva and the stomach acids and it can never go back to normal. (Steve)

The student post reflection data further revealed that students were cognizant of the various aspects of the nature of science and process of scientific inquiry reflected in the lesson. A key idea students commented on, as indicated in the following excerpt, was the emphasis of the lesson on the centrality of observations and evidence in developing inferences and forming arguments or conclusions.

One of the biggest parts of the nature of science and inquiry in this lab was the focus on us making lots of observations and just writing down what we were observing and predicting at all times. What was neat was that we used what we recorded to later make inferences about what's a chemical and a physical change. And we also had to use our observations to draw conclusions and back up our arguments in the class discussion. It really showed us that science really is based on observations and evidence. (Tina)

Students also commented on how the lesson had provided them a more realistic experience of science than their previous encounters with science. More than two third of the students stated that the lesson was the first to allow them the opportunity to experience the creative dimension of scientific inquiry as well as the tentativeness and evolution of scientific knowledge while they were, on a rather smaller scale, involved with the collection, analysis, and communication of their observations and inferences.

What really stood out to me was that we were not sure about our criteria. First we just developed some criteria but those really changed once we went through our observations and had to use evidence to back up our criteria. It kept changing as we compared and shared more ideas. It was difficult not knowing the full answer, but I guess that is how science really works. Scientists are uncertain about their conclusions too, but the explanations they come up with are the best explanations based on the data gathered. (Stephanie)

Some students, such as Lisa, also mentioned that this lesson had allowed them the opportunity to experience the cyclical nature of scientific inquiry that we had discussed earlier in the course.

This activity was in line with what we read about the myth of the scientific method. It was the only lab so far which allowed me to see that science is not linear. We even ended the lesson with more questions and uncertainty about what the different changes in matter are. We saw the going back and forth with data and with discussions within and among teams that are similar to the real process of science. (Lisa)

Working as a community of scientists was of interest to almost all students. This aspect of science may often be subtly inferred through class activities, but rarely do students have the opportunity to witness firsthand the social nature of science. Students reflected on the effectiveness of this approach in allowing them to better learn the concept and witness the social dimensions of science in action.

My group first thought the scenario was weird, but it really helped me see how science is done. Scientists don't just work individually in their labs. We had discussed this before but in the last two class sessions I really began to see that there has to be a lot of talking and collaboration for scientists to achieve what they do. The whole time we were acting like real scientists discussing, sharing ideas, changing and revising our ideas, and working together to build a solid argument. This wasn't easy but I think it has been the only lesson so far that has really nailed this for me. (Morgan)

In the process of reflecting on the lesson, students' reflection entries, and the video analyses, we realized that, as instructors, we were successful at providing our students with a rare opportunity to work collaboratively, similar to the scientific community, to construct their own set of criteria based on the evidence they had gathered. They were also given the freedom and flexibility to gather, represent, and communicate their data and conclusions in any fashion they judged most appropriate. This had allowed them to experience and observe how science is conducted in the scientific community.

\subsection{Students'Learning Experiences}

A dimension of the traditional lesson that we had found disconcerting was the minimal level of collaboration and communication among team members. Students' conversations were often limited to team members taking turn reading the procedures, assisting one another in locating a piece of information necessary for answering a question, or struggling together to balance the equations at the end. It was evident that students lacked interest or connection to the activity because they found it of little value or relevance. The student-instructor interactions during the traditional were similar in nature. Whole class discussions were limited to pre-activity instruction. The conversations between the instructors and students in each team focused primarily on procedural questions and 
clarification of confusions surrounding the content material. The questions we posed during our conversations with the teams were rudimentary as well and often included knowledge, comparison, observation, or at best application type questions.

One of our main goals in this action research project was to explore students' experiences during the learning process with the revised lesson. One theme that quickly emerged from the data was our students' noticeable interest and high level of engagement during this lesson. Their actions, interactions, and reflections indicated a keen sense of engagement in the various components of the lesson and demonstrated a high level of motivation and determination to investigate the question initially posed to them. In contrast to previous semesters, these students described finding themselves thrust in exciting experimentations, gathering evidence, repeatedly returning to their data and set of observations, proposing their individual ideas, bouncing around ideas and arguments, and further revising their ideas. It was evident from the video analyses and students' reflections, such as the one below, that since this lesson actively involved them in the learning process and constructing their own understanding of the concepts, students were more engaged than in prior lessons.

This lab was different and cool in that I had no idea what would happen in each experiment. It also made me more interested in categorizing them because our team was coming up with the criteria and we were doing what scientists do which is to go back and forth in discussing and analyzing the data. It was a long process but at least we were awake the whole time and enjoying the conversation. I felt I learned a lot just by listening to my peers and being really active. (Michele)

Students explicitly mentioned that their interest was in part due to the lesson's "relevancy" and having a "context and scenario" which, as one student phrased it, "made it seem more realistic than the other activities where we were just following the dull textbook steps" (Michael). Another student reiterated similar sentiments:

Our team was captivated because the scenario put us in charge of figuring it out and adding to the past theories. We no longer had easy definitions to work with. WE were charged with the task of creating those criteria and that was challenging but motivating at the same time. (Lindsay)

Finally, for a modest number of our students, who normally found science uninteresting and challenging, this activity provided an opportunity to be captivated by science and feel a sense of accomplishment upon completing the given task.

Even though students seemed to have profoundly enjoyed and learned from this lesson, our findings also revealed several issues that require attention and resolution. During our conversations with the teams, we observed that initially students expressed varying degrees of frustration and confusion about initiating the task of examining their data and developing the necessary criteria. At first, they considered this task to be "too open-ended," because they were not provided with the "necessary background information and stepwise instructions" as they had been previously accustomed to (Kristen). The initial source of exasperation for some of the students was simply the lack of certainty about the task and what constituted as criteria. Others felt frustrated that "there were no right or wrong answers" and that they were not provided with any specific guidelines in coming up with their criteria. Many expressed being "stuck" and did not know how to proceed.

Student 1 : Is the change in color always a physical?

Instructor: I don't know. Remember, you are coming up with the criteria.

Student 2: Like in the one where the acid was eating away at it that was chemical but the one we cut up the matches that was physical

Student 3: We are not sure what it is we have to do. How do we come up with the criteria?

Instructor: See if you can find a general trend or pattern among your observations rather than comparing one experiment to another and classifying them at this point.

The following conversation illustrates how some teams, rather than attempting to generate their criteria based on patterns from the data collected, began defining and using the terms physical and chemical change as they had recollected- albeit partially or incorrectly- from previous science experiences.

Student 1: We don't know how to come up with our own criteria. What do you mean with criteria?"

Instructor: Well, you are trying to expand on the original ideas presented in the scenario. If physical is just change in appearance, what does that mean? Based on your observations what would count as changes in appearance? So these are like rules or signs that you notice in your observations that can be used to distinguish between the two types of changes. 
Blank stares as they listen to the instructor.

Student 2: Our question on this one (pointing to one of the experiments) is so would this one be physical or chemical since it's just water?

Instructor: Well it depends on what you had before and after. Look at your notes. Remember, you need to generate the criteria based on your observations first.

Student 2: So would physical not just be the change in physical appearance? Cause like could you have a chemical like if I burnt a paper it is chemical but like its appearance changes too so it would be physical?

Instructor: Well what does the original statement about physical change indicate?

Student 3: physical is just changing appearance only-

Student 1: Oh so that's like tearing a piece of paper

Student 2: But with chemical it is not paper anymore. It's like ash. It's changing altogether.

Instructor: So that's something you may want to think about and add to your criteria: how did these differ from one another?

Moreover, as evident in the above excerpts, students' uncertainty caused them to constantly ask for reassurance from the instructor to determine if they were doing the task "correctly". Throughout the various stages of the lesson, there were countless students who constantly wanted to confirm their ideas with us to ensure that they were on "the right track" or developing their set of criteria "correctly." Even when they were initially carrying out the series of simple tests, they would ask whether they were putting the "right amount" of a substance or if they were setting up the apparatus "correctly." We quickly recognized, that early on students were not comfortable with the greater degree of flexibility and autonomy, so irrespective of the nature of the task, they initially asked more confirmation types of questions meant to reassure them they were "on the right track".

This concern for confirming the "appropriateness" of their approach or the "correctness" of their responses and criteria was coupled with a slight anxiety about how the approach in this lesson would align with the other course sections and the shared exam administered to all sections.

Student 1: So what if we don't come up with the correct criteria?

Instructor (smiling): Don't worry about being right or wrong. It is all about using your observation data as evidence for your argument.

Student 2: But you know there has to be a right answer. What if we say these criteria and this other group comes up with other criteria? How can we both be right?

Instructor: This is just the beginning of the lesson and we have ways to go. So don't worry about being right or wrong. Instead, focus on going through your observations and see if you can find any patterns.

Student 3: For example, how do we classify \#15? We had said it was chemical because we thought it was a change in identity, but now think it is physical. So how do we explain something like this on the exam?

Student 1: When will we find out the real answers?

Instructor: Well, at this point you are a community of scientists and you are trying to find out what distinguishes physical from chemical changes. So how can you do that based on the observations you gathered the other day?

Student 4: I am very confused because when we are younger they (teachers or texts) tell you this is physical change and this is chemical. I remember we did this. And they tell you this is what to look for in each type of change but we don't have that here.

Instructor: Well, let's think about what we discussed earlier about science. Do scientists have the answers before they embark on their explorations? Where have these definitions come from anyway?

Student 1: So it is the evidence that counts?

The team was mainly concerned with whether the definitions and criteria they were developing would be "sufficient" and "appropriate" for the exam which they believed would only include content specific questions. Their initial concerns were alleviated by the instructor's reassurance and reminders about the importance of developing observation, critical thinking, reasoning, and argumentation skills rather than a superficial learning of content.

What we found comforting through our analysis was that, through our encouragement and guidance, students 
were able to move beyond the early frustrations and concerns. Our sustained support and addressing students' concerns, coupled with our guiding questions that encouraged them to think independently and utilize their data, propelled them to work collaboratively and complete the task successfully. During the lesson and the subsequent video analysis, we observed a tremendous level of vitality and interaction among students that we found rather remarkable and contrary to the previous three years we had taught the course. Students were observed smiling, conversing, sharing information, sifting through papers and index cards on which they had recorded their observations, reflecting individually, and actively participating in various ways that indicated high levels of engagement in the activity as well as critical thinking and scientific discourse. Teams actively discussed every aspect of the lesson. Initial conversations revolved around possible approaches to collecting and organizing their observations. Their continuing discussions throughout the lesson revolved around the development of appropriate criteria and the subsequent categorization of the experiments based on these criteria. Students reflected that the engaging scenario, which called on them to act as a community of scientists, challenged them and encouraged critical thinking, greater engagement in the lesson, and increased team collaboration and communication.

I looked at the task you gave us as a challenge. Soon my entire team saw it that way. Even though it was very tough, especially at first, we really got to have a good discussion. We had to think like scientists and go back to our notes and observations over and over. We kept looking for some criteria to write down, but it only became possible when we kept bouncing ideas back and forth and when you came to our table it really helped guide us because your questions would make our discussions more clear. (Morgan)

Another student reflection further illuminates students' view of this lesson as one that encouraged increased communication and critical thinking because of the open-ended and problem-based nature of the lesson. Ashley discusses how they worked as a team to complete the challenge.

At times I felt my brain would explode from thinking so much. We did more thinking in today's lesson than I have in all my previous science courses. Because you didn't give us any criteria or definitions or background information or anything for that matter, we had to think through it all and figure things out on our own. Each question you asked us when you came to our table made us think even more. Going back through the observations and finding the patterns was a challenge and it took us a while to see it but we did! Everyone talked, threw out ideas, thought more and we were able to put our heads together and think and complete the task. (Ashley)

Yet another student's reflection highlights the inclusive nature of the collaborative interactions in this lesson. The student-centered and open-ended lesson structure necessitated collaboration and active involvement by all team members.

I don't think I have ever talked with my team members as much as I did today. We always tried to follow the lab instructions, but in this lesson there were no real instructions. We had to come up with so much of it and we couldn't do it alone. We had to talk and we had to throw out ideas and discuss them. It really got all of us involved. When we would be quiet for some time and just reflecting in our heads someone would say something and the discussion would continue. I really liked this collaboration. I am not saying it was easy, but I thought it was really productive. We did the impossible: we came up with the criteria! (Carol)

The following excerpt, from the latter part of a team conversation, illustrates a continual exchange of ideas and active contribution of all team members as referenced in the above reflective comments.

Instructor: Let's look at the two simple examples, the candle melting and the match breaking. How are they different from the rest?

Student 1: There is no reaction happening.

Instructor: What do you mean no reaction?

Student 2: Like there is no fizzing, no bubbling, no ...

Instructor: So you are automatically putting those under chemical. Okay, so that's one way to look at it. What else can we think about? If we heat the wax you have collected there, what will happen?

Student 2: It will melt and become liquidy.

Instructor: And if we cool it down what will happen?

Student 3: It will become firm and a solid.

Student 1: But with the match you can't do it over and over again 
Instructor: Right. That's true, but am I changing what I started up with?

Student 4: No, you are not changing the match into something completely different

Student 2: Just breaking it but not changing to anything different

Student 3: The chemical is like when you can't go back to the original like the two liquids we mixed together. That could be one of our criteria for chemical.

Student 1: So like if we broke the match and it can't go back to its original state then wouldn't the match be chemical?

Student 3: The wood is wood but the two liquids we mixed together I am not sure maybe we can separate them but maybe not once it is yellow solid we probably can't go back to the two liquids. So wouldn't it be chemical? Because it changed to something completely new and we can't reverse it

Student 1: Right. I agree.

The above reflection and team discussion excerpts also highlight the authors' roles as the instructors. As evident in these captions, we played a major role in guiding and facilitating the inquiry process. We began by asking questions that encouraged students to share what they were observing in the initial stage of the lesson. Prompting them to keep track of and organize their observation data was critical because some of the teams were recording minimal and incomplete data. By asking them questions, we encouraged them to make additional and more detailed observations. Afterward in the discussion stage, our questions focused on encouraging them to examine their data, look for patterns, come up with ways to categorize the types of changes, and formulate their criteria.

Especially in the beginning of the lesson when students were first attempting to come up with their set of criteria and expressed a sense of frustration and being "stuck", we asked questions that facilitated their thinking and assisted with advancing their discussion. At times, these questions urged students to express some of the ideas they would otherwise be hesitant to express and, at other times, led to revisions to their ideas that strengthened their criteria. Our line of questioning in the above conversation, as in other cases, allowed students to work through their developing ideas. These types of guiding questions often triggered further discussions and reflection among team members. There were numerous similar cases where we asked some questions only to have the team carry out the remainder of the discussion on their own while we remained silent and listened to their arguments and ideas, interjecting only as necessary.

\section{Discussion}

This action research project proved to be an enlightening process that enabled us to utilize "systematic, self-critical inquiry" (Capobianco, 2007) to explore, reflect upon, and improve our teaching practices and students' learning experiences. Because action research is an ongoing cycle, what we have learned will be utilized to continue the process of exploration, reflection, and improvement, not only with this lesson and course, but other similar contexts as well. Additionally, we hope that our reflections and the lessons learned in this project may be insightful for other science educators as well. Our findings regarding students' understanding and learning outcome were encouraging. Their responses and reflections, which were based on the evidence they had collected or the discussions that occurred throughout the lesson, indicated an in-depth understanding of the concept of change in matter. More importantly, they had gained a better understanding of the nature of science and scientific inquiry through their own experiences in this lesson.

In this study, we were even more interested in students' learning experiences that generated such learning outcomes. Because both the process of scientific inquiry and students' conceptual knowledge are socially constructed, it is essential that we focus on and seek to better understand the often-neglected dynamics of this social learning process and students' experiences and interactions in such a learning environment. Doing so will better enable us to bring further improvements to our lessons and courses in order to maximize students' learning and learning experiences. The analysis of the learning experience indicated that students were highly engaged and interested in this lesson. Throughout the lesson, they were actively involved in performing the initial tests, making observations, discerning and discussing patterns within their data, and collaborating and communicating possible ways to develop the necessary criteria. It is important to offer elementary PSTs such inquiry experiences in order to allow them to gain a more in-depth and robust understanding, be actively involved in the process of scientific inquiry and discourse, take pleasure in their learning experience, and finally feel a sense of achievement.

Throughout the reflection process, we also contemplated and discussed concerns and challenges that should be considered for future revisions to this lesson and the course in general as well as any other similar course 
development and action research efforts. We felt that the lesson should be a more cyclical process that better reflects the process of scientific inquiry and the $5 \mathrm{E}$ learning cycle model. With such an approach, students would perform a few tests, have an opportunity to discuss their observations and seek emerging patterns, and then do additional tests to collect further observations and make additional inferences. Developing inquiry lessons that are better aligned with the recursive nature of exploration and explanation stages of the learning cycle will better reflect the cyclical nature of scientific inquiry and might also reduce the level of frustration students initially experienced in discerning patterns in their observation data. Similarly, we discussed incorporating an additional explanation stage to allow students to examine texts and online resources, as well as consult with scientists, to ascertain how the scientific community has approached this task and the criteria they have developed. This would allow students the opportunity to compare their experiences and conclusions with those of the scientific community and alleviate some of their initial concerns and frustrations regarding the open-endedness of the lesson and the lack of a clear correct or incorrect answer.

Students' initial concerns and frustrations suggested that such learning opportunities, if meant to be effective, should not be isolated cases. Students should have numerous encounters with this type of learning throughout the course in order to ease the process of acclimation to inquiry-based learning and allow students to develop the necessary skills and attitude. Reconfiguring students' habits of learning, especially in science, will take time and require a concerted, repeated effort to provide them with similar experiences, which will in turn develop their critical thinking, problem solving, inquiry, and reasoning skills. An additional source of anxiety, briefly felt by some students early in the lesson, was their concern about the upcoming course exam. Revision of the course material to align with inquiry-based learning will be most successful and enduring if accompanied with a revision and restructuring of the assessment practices in such courses. Reforming the instructional approach in these courses without altering the assessment component can prove to be counterproductive by increasing students' frustrations, which may likely interfere with their learning.

Overall, this action research study has highlighted that inquiry-based science lessons and content courses have the potential to improve elementary PSTs' knowledge, science learning experience, and views of nature of science and scientific inquiry. The findings have implications for science educators interested in science content course development for PSTs as well as science teachers at other levels who may be interested in exploring students' science learning experiences.

\section{References}

Abell, S. K., \& Bryan, L. S. (1997). Reconceptualizing the elementary science methods course using a reflection orientation. Journal of Science Teacher Education, 8, 153-166. http://dx.doi.org/10.1023/A:1009483431600

Buck, G., \& Cordes, J. (2005). An Action Research Project on Preparing Teachers to Meet the Needs of Underserved Student Populations. Journal of Science Teacher Education, 16(1), 43-64. http://dx.doi.org/10.1007/s10972-005-6991-x

Bybee, R. W. (1997). Achieving Scientific Literacy. Portsmouth, N.H.: Heinemann.

Carr, W., \& Kemmis, S. (1986). Becoming critical: Education, knowledge, and action research. London: Falmer Press.

Capobianco, B. M. (2007). Science teacher' attempts at integrating feminist pedagogy through collaborative action research. Journal of Research in Science Teaching, 44(1), 1-32. http://dx.doi.org/10.1002/tea.20120

Elliott, J. (1991). Action research for educational change. Philadelphia: Open University Press.

Feldman, A., \& Capobianco, B. M. (October, 2000). Action research in science education. ERIC Digest: Clearinghouse for Science, Mathematics, and Environmental Education [SE 064 309]. Retrieved from $\mathrm{http}: / / \mathrm{www}$.ericse.org/digests/dse00-01.html

Feldman, A., \& Minstrell, J. (2000). Action research as a research methodology for the study of the teaching and learning of science. In E. Kelly, \& R. Lesh (Eds.), Handbook of research design in mathematics and science education. Mahwah, NJ: Lawrence Erlbaum Associates.

Ginns, I. S., \& Watters, J. J. (1990). A longitudinal study of preservice elementary teachers' personal and science teaching efficacy. Reports-Research/Technical ED 404127.

Hewson, P. W., Tabachnick, R. B., Zeichner, K. M., Blomerk, K. B., Meyer, H., Lemberger, J., Marion, R., Park, H., \& Toolin, R. (1999). Educating prospective teachers of biology: Introduction and research methods. Science Education, 83(3), 247-273. http://dx.doi.org/10.1002/(SICI)1098-237X(199905)83:3<247::AID-SCE1>3.0.CO;2-C 
Kemmis, S. (1988). Action research in retrospect and prospect. Geelong, Victoria, Australia: Deakin University Press.

Lincoln, Y. S., \& Guba, E. G. (1985). Naturalistic inquiry. Newbury Park, CA: Sage Publications.

Loucks-Horsley, S., Hewson, P. W., Love, N., \& Stiles, K. E. (1998). Designing professional development for teachers of science and mathematics education. Thousand Oaks, CA.: Corwin.

Loucks-Horsley, S., Love, N., Stiles, K. E., Mundry, S., \& Hewson, P. W. (2003). Designing professional development for teachers of science and mathematics education (2nd ed.). Thousand Oaks, CA.: Corwin.

Loughran, J. (1996). Developing reflective practice: Learning about teaching and learning through modeling. London: Falmer Press.

National Research Council. (1996). National science education standards. Washington, DC: National Academy Press.

National Research Council. (2000). Inquiry and the National Science Education Standards. Washington DC : National Academy Press.

Noffke, S. (1997). Professional, personal, and political dimensions of action research. Review of Research in Education, 22, 305-343.

Palmquist, B. C., \& Finley, F. N. (1997). PSTs' views of the nature of science during a postbaccalaureate science teaching program. Journal of Research in Science Teaching, 34(6), 595-615. http://dx.doi.org/10.1002/(SICI)1098-2736(199708)34:6<595::AID-TEA4>3.0.CO;2-I

Rice, D., \& Roychoudhury, A. (2003). Preparingmore confident preservice elementary science teachers: One elementary science methods teacher's self-study. Journal of Science Teacher Education, 14, 97-126. http://dx.doi.org/10.1023/A:1023658028085

Riggs, I. M. (1991). Gender differences in primary science teacher-efficacy. Paper presented at the Annual Meeting of the American Educational Research Association, Chicago, IL.

Stenhouse, L. (1975). An introduction to curriculum research and development. London: Heinemann.

van Zee, E. H. (1998). Fostering elementary teachers' research on their science teaching practices. Journal of Teacher Education, 49, 245-254. http://dx.doi.org/10.1177/0022487198049004002

van Zee, E., Lay, D., \& Roberts, D. (2003). Fostering collaborative inquiries by prospective and practicing elementary and middle school teachers. Science Education, 87, 588-612. http://dx.doi.org/10.1002/sce.10070 